\title{
EMERGENCY OBSTETRIC HYSTERECTOMY
}

\section{FCPS}

Associate Professor

Gynecology \& Obstetrics Department

PMC/Allied Hospital, Faisalabad

2. FCPS,

Senior Registrar,

Gynecology \& Obstetrics Department, PMC Allied Hospital, Faisalabad.

3. FCPS

Registrar,

Madina Teaching Hospital, Faisalabad.

\section{Correspondence Address:}

Dr. Sarwat Ara,

92-Faisal Gardens,

West Canal Road

Faisalabad.

sarwatara fcps@hotmail.com

\section{Dr. Sarwat Ara', Dr. Umbreen², Dr. Fouzia ${ }^{3}$}

ABSTRACT... Background: Emergency hysterectomy in obstetric practice is generally performed in the setting of life-threatening hemorrhage which fails to be controlled by conservative management. Objective: To review 8 years' experience of emergency obstetric hysterectomy in a teaching hospital. Study Design: A retrospective descriptive study based on hospital data of 156 patients undergoing emergency Obstetric hysterectomy. Settings: Obs. \& Gynae. Department Unit-I, PMC Allied Hospital Faisalabad. Methods: This was a retrospective review carried out from March 2004 to Feb 2012 Main outcome measures were frequency, indications, associated risk factors and maternal morbidity and mortality associated with emergency peripartum/obstetric hysterectomy. Results: During 8 years there were total 156 $(0.38 \%, 3.8$ per 1000$)$ emergency obstetric hysterectomies out of which there were 46 caesarian hysterectomies, 65 post partum, 45 for ruptured uterus with total number of delivery 40062 . Number of hysterectomies was 48 in the first 4 years of the study (March 2004- Feb 2008) and during the last 4 years (March 2008- Feb 2012) it was 108. Maximum obstetric hysterectomies were in para $3-5(53.20 \%)$ and in $26-30$ years age group $(35.89 \%)$. The most common indication for hysterectomy was uterine atony $(44.23 \%)$ followed by uterine rupture $(28.85 \%)$, Placenta accreta (14.745\%) and placenta previa (11.53\%). The maternal mortality was $6.41 \%(10$ patients). In this series $80 \%$ patients were referred from other areas. Conclusions: Frequency of emergency Obstetric hysterectomy is high in our tertiary center and it is continuously increasing due to increased referral of patients. The mortality and morbidity of performing obstetric hysterectomy is higher in patients referred from outside hospital.

Key words: $\quad$ Obstetric hysterectomy, peripartum hysterectomy, atony, post partum hemorrhage, abnormal placentation, ruptured uterus.

Article Citation: Ara S, Umbreen, Fouzia. Emergency obstetric hysterectomy. Professional Med J 2015;22(1):100-105.

\section{INTRODUCTION}

Peripartum or Emergency obstetric hysterectomy is defined as any hysterectomy performed within 24 hours of a delivery ${ }^{1}$. It includes both postpartum and cesarean hysterectomy. It is a vital procedure to save life of a mother although it is opted as a desperate attempt when all measures fail to control catastrophic hemorrhage from placental bed in previa or moribund adherence of placenta or due to uterine atonia ${ }^{2}$. Emergency obstetric hysterectomy was first performed in the 19th century to lessen the high maternal mortality and morbidity related with the caesarian delivery. The indications were mainly grave sepsis and hemorrhag ${ }^{3}$. Subsequently common indications for emergency peripartum hysterectomy were uterine rupture and uterine atony ${ }^{4}$. Over the past 2-3 decades indication for hysterectomy were uncontrollable haemorrhage due to placenta accreta or uterine atonia ${ }^{5}$. The risk factors for abnormal placcentation include scarred uterus owing to previous cesarean section, myomectomy, dilatation and curettage, multiparty and older age group.

As reported by Clarke $^{6}$ et al incidence of placenta previa increases from $0.5 \%$ in general population to $3.9 \%$ after one caesarean section and up to $10 \%$ after four caesarean sections. The incidence of placenta accreta is $5 \%$ in patients with placenta previa and one caesarean scar; while moribund placental adherence increases to $67 \%$ with previous four caesarean sections ${ }^{4}$.

\section{MATERIALS AND METHODS}

Data of all patients admitted in labour ward from March 2004 to Feb 2012, regarding frequency of hysterectomy, maternal age, parity, causes 
of hemorrhage, type of hysterectomy and its complications, was retrieved from yearly maintained registers / performas of obstetrical hysterectomy.

\section{Exclusion Criteria}

Lower segment caesarian sections performed on elective list. Obstetric hysterectomy performed after 24 hours of delivery.

\section{Inclusion Criteria}

All normal vaginal deliveries and emergency caesarian sections and all obstetric hysterectomies done within 24 hours of delivery.

In our setup emergency obstetric hysterectomy is mostly performed by senior obstetrician, junior obstetricians and senior residents are not allowed to proceed for obstetric hysterectomy.

\section{RESULTS}

Total number of deliveries (normal vaginal and emergency caesarean) during the study period was 40062 out of which 156 emergency obstetric hysterectomies were undertaken; these were 65 postpartum, 46 Caesarian, 45 hysterectomies after ruptured of gravid uterus frequency being $0.38 \%$ (3.8 in 1000 deliveries). In the first 4 years (2004-2008) total number of emergency obstetric hysterectomies was 48 while in the last 4 years (2008-2012) they were 108 showing the increasing trends in the procedure.

\begin{tabular}{|c|c|c|c|}
\hline Study & Total hysterectomies & Duration & Incidence per 1000 deliveries \\
\hline Glaze $S$ et al ${ }^{1}$ & 87 & 8 year (1999-2006) & 0.8 \\
\hline Christopoulos et al ${ }^{5}$ & 15 & 14 year (1994 to 2009) & .92 \\
\hline Clark et $\mathrm{al}^{6}$ & 70 & 4 year (1978 to 1982) & 1.02 \\
\hline Zelop,et,al" & 117 & 9 year (1983 to 1991$)$ & 1.55 \\
\hline Nusrat Shah ${ }^{8}$ & 69 & 5.5 year (2002 to 2007$)$ & 6.8 \\
\hline Gupta, et al ${ }^{9}$ & 169 & 5 year (1976 to 1980.$)$ & 1.69 \\
\hline Authors' Study & 156 & 8 year ( 2004 to 2012 ) & 3.8 \\
\hline
\end{tabular}

Table-I: Comparison of incidence of obstetric hysterectomy in different studies

The three most common causes were uterine atony in 69 women (44.23\%) followed by ruptured uterus in 45 women $(28.85 \%)$ and morbidly adherent placenta in 23 women (14.74\%), placenta previa in 18 (11.53\%) and fibroid uterus in one patient.

\begin{tabular}{|c|c|c|c|}
\hline \multicolumn{2}{|r|}{ Indication } & No. of patients & \%age \\
\hline \multirow{2}{*}{$\begin{array}{l}\text { Uterine } \\
\text { atony }\end{array}$} & Post NVD & 65 & \multirow{2}{*}{44.23} \\
\hline & Post LSCS & 4 & \\
\hline \multicolumn{2}{|c|}{$\begin{array}{l}\text { Uterine rupture, trauma or } \\
\text { broad ligament haematoma }\end{array}$} & 45 & 28.84 \\
\hline \multicolumn{2}{|c|}{$\begin{array}{l}\text { Moribund adhesion of placenta } \\
\text { increta \& percreta }\end{array}$} & 23 & 14.74 \\
\hline \multicolumn{2}{|c|}{ Placenta previa } & 18 & 11.53 \\
\hline \multicolumn{2}{|c|}{ Fibroid uterus } & 1 & 0.64 \\
\hline \multicolumn{2}{|l|}{ Total } & 156 & 99.98 \\
\hline
\end{tabular}

Table-II: Main indications for EOH group followed by $31.41 \%, 18.58 \%$ and $14.10 \%$ in $31-35,20-25$ years, and $36-40$ years age groups respectively.

\begin{tabular}{|c|c|c|}
\hline Age in years & No. of patients & \%age \\
\hline $20-25$ & 29 & 18.58 \\
\hline $26-30$ & 56 & 35.89 \\
\hline $31-35$ & 49 & 31.41 \\
\hline $36-40$ & 22 & 14.1 \\
\hline Total & 156 & 99.98 \\
\hline Table-III. Distribution of emergency obstetric \\
\hline
\end{tabular}

Para 3-5 was most vulnerable group (83 patients, $53.20 \%$ ) followed by $20.51 \%, 17.30 \%$ and $8.97 \%$ in $\mathrm{P}_{6-8}, \mathrm{P}_{0-2}$ and $\mathrm{P}_{9-11}$ groups respectively.

Maximum 56 (35.89\%) emergency obstetric hysterectomies were done in $26-30$ years age 


\begin{tabular}{|c|c|c|}
\hline Parity & No. of patients & \%age \\
\hline $\mathrm{P}_{0}-\mathrm{P}_{2}$ & 27 & 17.30 \\
\hline $\mathrm{P}_{3}-\mathrm{P}_{5}$ & 83 & 53.20 \\
\hline $\mathrm{P}_{6}-\mathrm{P}_{8}$ & 32 & 20.51 \\
\hline $\mathrm{P}_{9} \mathrm{P}_{11}$ & 14 & 8.97 \\
\hline Total & 156 & 99.98 \\
\hline
\end{tabular}

Table-IV: Number of patients according to parity

Ten women died; giving mortality of $6.41 \%$ out of these $8(5.12 \%)$ were in group A (referred) and $2(1.28 \%)$ in group $B$ (booked). These were due to DIC following acute blood loss in 4, prolonged hypovolemic shock 4 , septicemia 1 and anesthesia complication in 1.

Risk factors were identified in three most common indications for hysterectomy. These risk factors for uterine atony were induction of labour outside hospital 20, injudicious use of oxytocin 20, placental abruption in 8 , Chorioamnionitis 6 , twin delivery 3 and inversion of uterus in 2 patients. While in ruptured uterus 17 patients had prior uterine scar, injudicious use of oxytocin in 10, Manipulation in 4, Obstructed labour 3 , cervical tears extending up to the uterus 3 and 2 had instrumental delivery. Considering morbidly adherent placenta in 22 out of 23 women had prior caesarean .In placenta previa 14 out of 18 had either previous surgery or curettage.

\begin{tabular}{|c|c|c|c|}
\hline $\begin{array}{c}\text { Type of } \\
\text { obstetric } \\
\text { hysterectomy }\end{array}$ & Risk factors & Number & Total \\
\hline \multirow{7}{*}{ Postpartum } & Induction of labour & 20 & \multirow{7}{*}{65} \\
\hline & $\begin{array}{c}\text { Injudicious use of } \\
\text { oxytocin }\end{array}$ & 10 & \\
\hline & Abruption & 8 & \\
\hline & Chorio aminionitis & 6 & \\
\hline & Twin delivery & 3 & \\
\hline & Inversion & 2 & \\
\hline & No risk & 16 & \\
\hline
\end{tabular}

\begin{tabular}{|c|c|c|c|}
\hline \multirow{6}{*}{ Rupture } & Scarred uterus & 17 & \multirow{6}{*}{45} \\
\hline & $\begin{array}{l}\text { Instrumental } \\
\text { delivery }\end{array}$ & 2 & \\
\hline & Obstructed labour & 3 & \\
\hline & $\begin{array}{l}\text { Manipulation for } \\
\text { second twin }\end{array}$ & 2 & \\
\hline & $\begin{array}{c}\text { Manual removal of } \\
\text { placenta }\end{array}$ & 2 & \\
\hline & $\begin{array}{l}\text { Injudicious use of } \\
\text { oxytocin }\end{array}$ & 19 & \\
\hline \multirow{5}{*}{$\begin{array}{c}\text { Caesarian } \\
\text { hysterectomy }\end{array}$} & $\begin{array}{c}\text { Abnormal } \\
\text { placentation }\end{array}$ & 23 & \multirow{5}{*}{46} \\
\hline & Placenta previa & 18 & \\
\hline & Fibroid & 1 & \\
\hline & $\begin{array}{c}\text { Abruption (atonia } \\
\text { due to couvalair } \\
\text { uterus) }\end{array}$ & 2 & \\
\hline & Uterine atonia & 2 & \\
\hline Grand total & & 156 & 156 \\
\hline
\end{tabular}

$88 \%$ were markedly anemic. Minimum blood transfusion of 3 units and maximum of 8 units were given. Only $20 \%$ of women were booked. Total hysterectomy was undertaken in $49(31.41 \%)$ and subtotal in 107 (68.59\%.) women.

\begin{tabular}{|c|c|c|}
\hline Type & Number & \%age \\
\hline Total hysterectomy & 49 & 31.41 \\
\hline $\begin{array}{c}\text { Subtotal } \\
\text { hysterectomy }\end{array}$ & 107 & 68.59 \\
\hline Total & 156 & 100.00 \\
\hline Table-VI. Type of hysterectomy \\
\hline
\end{tabular}

Morbidity was noted in 68 (43.59. \%) out of which 60 were in group A (referred) and 8 (5.13\%) in group $B$ (booked). Major intra-operative complications were bladder injury 7 (4.49\%) injury to ureter $2(1.28 \%$,) rectum 1 (0.64\%). Extended surgery included repair of bladder in 7 , internal iliac ligation 7 (five at the time of hysterectomy while two were done at re laparotomy for secondary hemorrhage) and colostomy 1 patient. Out of 2 internal iliac ligations, one had injury to rectum at re laparotomy. Postoperative wound infection $15(9.62 \%)$, DIC $5(3.21 \%)$, burst abdomen 4 (2.56\%), re laparotomy for secondary 
hemorrhage $3(1.92 \%)$, vesico vaginal fistula in 2 $(1.28 \%)$, septicemia in $1(0.64 \%)$, paralytic ileus in one $(0.64 \%)$ patient, hospital stay more than 10 days $10(6.41 \%)$ patients. ICU admission needed by $15(9.61 \%)$ patients. Morbidity related to type of hysterectomy was not significant

\begin{tabular}{|l|c|c|c|c|}
\hline Complication & $\begin{array}{c}\text { Group } \\
\text { (referred) }\end{array}$ & $\begin{array}{c}\text { Group B } \\
\text { (booked) }\end{array}$ & \multicolumn{2}{|c|}{ Total } \\
\hline Bladder injury & 5 & 2 & 7 & $(4.49 \%)$ \\
\hline ICU admission. & 12 & 3 & 15 & $(9.62 \%)$ \\
\hline septicemia & 1 & - & 1 & $(0.64 \%)$ \\
\hline $\begin{array}{l}\text { Wound } \\
\text { infection }\end{array}$ & 13 & 2 & 15 & $(9.62 \%)$ \\
$\begin{array}{l}\text { Burst } \\
\text { abdomen }\end{array}$ & 4 & - & 4 & $(2.56 \%)$ \\
\hline DIC & 5 & - & 5 & $(3.21 \%)$ \\
\hline $\begin{array}{l}\text { Thrombosis } \\
\text { Relaparotomy } \\
\text { for internal } \\
\text { hemorrhage }\end{array}$ & 1 & - & 1 & $(0.64 \%)$ \\
\hline Paralytic ileus & 1 & - & 3 & $(1.92 \%)$ \\
\hline Gut injury & 1 & - & 1 & $(0.64 \%)$ \\
\hline Ureteric injury & 2 & - & 2 & $(1.28 \%)$ \\
\hline $\begin{array}{l}\text { Vesico-vaginal } \\
\text { fistula }\end{array}$ & 2 & - & 2 & $(1.28 \%)$ \\
\hline $\begin{array}{l}\text { Prolonged } \\
\text { hospital >10 } \\
\text { days }\end{array}$ & 10 & - & 10 & $(6.41 \%)$ \\
\hline $\begin{array}{l}\text { Anesthesia } \\
\text { Complication }\end{array}$ & 1 & - & 1 & $(0.64 \%)$ \\
\hline \begin{tabular}{l} 
Total \\
\hline
\end{tabular} & 60 & 8 & $68(43.59 . \%)$ \\
\hline
\end{tabular}

Table-VII. Intra and post operative complications

\section{DISCUSSION}

Emergency obstetric hysterectomy is unpleasant to perform especially in primiparous or Para 2. There is no doubt that it has to be opted to decrease maternal mortality and morbidity though procedure itself is said to be associated with many complications.

In the present study we have an incidence of $0.38 \%$ (3.8 per 1000$)$. It is a very high incidence if we compare it with studies in developed ${ }^{1,5,6,7}$ and other developing countries ${ }^{9,}{ }^{19}$ while less than in nigeria $^{12}$ whereas two recent studies in Pakistan make it less in one ${ }^{8}$ at the same time comparable with the other ${ }^{20}$.
In this study maximum (35.89\%) emergency obstetric hysterectomies were done in 26-30 years group (exactly the same described in one study $^{23}$ ). Para ${ }_{3-5}$ was most vulnerable group followed by Para ${ }_{6-8}$ In Najam10 R et al study Parity distribution revealed the incidence of this radical and life saving surgery was more in patients who were para 5 and above.; whilst in our case it is max in $\mathrm{P}_{3}-\mathrm{P}_{5}$ followed by $\mathrm{P}_{6}-\mathrm{P}_{8}$,

$S$ Ahmad $^{4}$ highlighted that the major indication for cesarean hysterectomy was uterine rupture followed by placenta previa, uterine atony and abnormal placentation that is increta/accerta/ percreta. It is contrary to our results where main indication was uterine atony followed by uterine rupture, Placenta previa, abnormal placentation. These are partly similar to Clark et al study ${ }^{6}$ (report). While comparing current study with alike circumstance ${ }^{11}$ in Pakistan where uterine atony followed by uterine rupture and abnormal placentation run in conformity with our results. Uterine rupture is parallel with study of other developing country, Nigeria ${ }^{12}$, where it is $28.6 \%$ very near to present study because of the similarity of circumstances.

Abnormal placentation was the primary cause of cesarean hysterectomy in many studies ${ }^{7,12,13}$ where identifiable risk factors for abnormal placentation were prior cesarean delivery and placenta previa. It is also picked from our study that $95.6 \%$ (22 out of 23) patients with placenta accreta or percreta had previous cesarean deliveries.

Over the past few decades indications for emergency hysterectomy have revealed a change of trend. It is attributable to previous history of caesarian section which increases the risk for hysterectomy by raising the incidence of placenta previa and abnormal placentation.

In spite of the above facts, obstetric hysterectomy due to uterine atony is still high in developing countries. It is considerably associated with factors like unbooked status, labour induction/ augmentation outside hospital, unsupervised delivery, chorioamnionitis due to prolonged labor 
and trial by traditional birth attendants.

Subtotal hysterectomy is preferred procedure than total hysterectomy owing to more safety and quickness ${ }^{14}$. It connected with less post operative morbidity ${ }^{14,15}$. Associated morbidity in relation to type of hysterectomy was not significant in our study. Our observed experience regarding type of hysterectomy is different from many studies ${ }^{8,16}$ but similar with.others ${ }^{14,15}$. Currently the proportion of subtotal hysterectomy performed for Emergency Peripartum Hysterectomy ranges from 53 to $80 \%{ }^{14}$. In our study $68.59 \%$ underwent sub-total hysterectomy. Total hysterectomy was $89.3 \%$ in. Amos et, al ${ }^{22}$ study while it was $31.41 \%$ in present study .It was further noticed that most of the time hemorrhage in uterine atonia and uterine rupture (not involving the lower uterine segment) responded to sub total hysterectomy but 7 patients underwent internal iliac ligation along with sub-total abdominal hysterectomy. Associated morbidity in relation to type of hysterectomy was not significant in our study

The late referral and delayed appearance to the hospital, associates emergency obstetric hysterectomy with high maternal morbidity and mortality ${ }^{17}$. Maternal mortality $6.41 \%$ in our study is more than in developed world ${ }^{5,7,22}$ but comparable with study in Pakistan ${ }^{21}$ and other developing countries ${ }^{12,16.18}$. Al-Sibai ${ }^{18}$ extracted that mortality is dependent on severity of indication for emergency obstetric hysterectomy and condition of patient at the time of performing surgery.

Our experience is no more different from Al-Sibai, that most patients are in such a deteriorating condition at the time of initial presentation to the hospital which severely affects the outcome of patient. More over Poverty, unbooked, uneducated status of patient, injudicious use of oxytocin, non availability of transportation, further add to morbidity and mortality. Morbidity (43.59 $\%$ ) remained high in our study but less than described in other studies ${ }^{7,22}$.

Our complications of urinary tract injury including vesic- vaginal fistula (7.05\%) and re-exploration for persistent hemorrhage (1.92\%) are not very high as compared to $22.2 \%$ and $12.5 \%$ respectively in Lau WC study ${ }^{19}$ and intra operative urologic injury $9 \%^{7}$. Prompt surgical intervention, quick resuscitation, management ${ }^{18}$ and expertise ${ }^{10,23}$ of surgeon minimize morbidity and mortality. Postoperatively we found DIC, wound infection/ febrile illness, burst abdomen; which fortunately appeared to be less than described in similar locality ${ }^{20}$.

Need for blood transfusion remained $100 \%$ in above $\mathrm{e}^{20}$ and present study as compared to $87 \%$ in another study ${ }^{7}$. Paralytic ileus not very significant but postoperative stay more than 10 days was noted in $6.41 \%$ and ICU admission was needed by $9.61 \%$ patients contrary to $53 \%$ admission requirement to the intensive care unit observed in one study ${ }^{1}$. Post operative sepsis was $10.26 \%$ while it was $37 \%$ reported in one study ${ }^{23}$.

\section{CONCLUSIONS}

Frequency of emergency Obstetric hysterectomy is high in our tertiary center and it is continuously increasing due to increased referral of patients. It is a valuable life saving measure opted for uncontrollable hemorrhage. The associated morbidity and mortality with the procedure can be reduced by rapid resuscitation of patient, immediate availability of blood, timely decision, quickness and experience of obstetrician.

Copyright@ 05 Nov, 2014.

\section{REFERENCES}

1. Glaze S; Ekwalanga P; Roberts G; Lange I; Birch C; Rosengarten A; Jarrell J; Ross S SO Peripartum hysterectomy: 1999 to 2006. Obstet Gynecol. 2008 Mar; 111(3):732-8.

2. Awan N, Bennett MJ, Walters WA. Emergency peripartum hysterectomy: a 10-year review at the Royal Hospital for Women, Sydney. Aust N Z J Obstet Gynaecol 2011 Jun;51(3):210-5.

3. Alsayali AR; Baloul SM. Emergency obstetric hysterectomy: 8-year review at Taif Maternity Hospital, Saudi Arabia. Annals of Saudi Medicine 2000; 20(56):454-456.

4. Ahmad SN, Mir IH, Emergency Peripartum hysterectomy: Experience at apex hospital of Kashmir Valley. The internet $\mathrm{J}$ ofGynecol and Obstet 
$2007 ; 8: 2$

5. Christopoulos $P$, Hassiakos $D$, Tsitoura A, Panoulis $K$, Papadias $K$, Vitoratos $N$. Obstetric hysterectomy: a review of cases over 16 years. J Obstet 2011;31(2):13941.

6. Clark SL, Yeh SY, Phelan JP, Bruce S, Paul RH. Emergency hysterectomy for obstetrical hemorrhage. Obstet Gynecol 1984; 64: 376-80.

7. Zelop CM, Harlow BL, Frigoletto FD, Safon LE, Saltzman Dh. Emergency peripartum hysterectomy. Am J Obstet Gynecol 1993; 168: 1443-48.

8. Nusrat shah, Nusrat $\mathrm{H}$ Khan. Emergency obstetric hysterectomy: a review of 69 cases. Rawal med J 2009 Jan - Jun; 34(1):75-8.

9. Gupta $U$, Anjana. Changing trends in emergency hysterectomy in obstetric practice in a large teaching hospital. The Journal of Obstetrics and Gynecology of India.42; 2: 169-73 (ㅁ)

10. Najam R Bansal P, Sharma R, Agarwal D. Emergency Obstetric Hysterectomy: A Retrospective Study at A tertiary Care Hospital Journal of Clinical and Diagnostic Research. 2010 Agust ;(4): 2864-2868

11. Alia B, Razia A, Asma G, Arif T. Peripartum hysterectomy. Ann King Edward Med Coll 2007 Jan - Mar; 13(1):111-2.

12. Chisara C. Umezurike, Paul A. Feyi-Waboso ' Charles A, Adisa. Peripartum hysterectomy in Aba southeastern Nigeria. Australian and New Zealand Journal of Obstets and Gynaecol 2008 Dec 48(6) 580 - 582.

13. Bakshi S, Meyer BA. Indications for and outcomes of emergency peripartum hysterectomy. A five-year review. J Reprod Med. 2000 Sep; 45(9):733-7.

14. Lovina S.M. Machado. Emergency peripartum hysterectomy :incidence, indication,risk factors, outcome. N Am J Med Sci 2011 August; 3(8): 358-361.
15. Megafu $U$. Factors influencing maternal survival in ruptured uterus. Int J Gynacol Obstet 1985; 23:475 -80.

16. Zorlu CG; Turan C; Isik AZ; Danisman N; Mungan T; Gokmen O SO. Emergency hysterectomy in modern obstetric practice. Changing clinical perspective in time. Acta Obstet Gynecol Scand 1998 Feb; 77(2):1869.

17. Onwuudiegwu U, Okonofua F. Emergency obstetric hysterectomy in a semi-urban hospital. Nig Med $\mathrm{J}$ 1993; 2 (2): 54-7.

18. Al-Sibai MH, Rahman J; Rahman MS; Butalack F. Emergency hysterectomy in obstetrics : a review of 117 cases. Aust N Z J Obstet Gynaecol 1987 Aug; 27(3):180.

19. Lau WC; Fung HY; Rogers MS. Ten years experience of caesarean and postpartum hysterectomy in a teaching hospital in Hong Kong. Eur J Obstet Gynecol Reprod Biol 1997 Aug; 74(2):133-7.)

20. Nusrat Nisar, Nisar Ahmed Sohoo. Emergency peripartum hysterectomy: frequency, indications and maternal outcome. Ayub Med Coll Abottabad 2009 Jan - Mar ;21(1):48-51.

21. Sumera T, Mahmood A, Samina A. Indication and maternal outcome of emergency Peripartum hysterectomy. Pak J Med Sci 2003 July- Sep ;19. (3): $182-6$.

22. Amos AA, Olufemi AO. Emergency obstetric hysterectomies : how many are potentially preventable?: 28- Year experience in Saskatoon. J Surg 2004;20:81-7.

23. Anjali K, Rekha S. Obstetric hysterectomy: a retrospective study at a tertiary care centre. Int $\mathrm{J}$ Reprod Contracept Obstet Gynecol 2013; 2 (4):562-565. 